\title{
Estrutura térmica identificada por transectos móveis e canal termal do Landsat 7 EM cidade tropical ${ }^{1}$
}

\author{
Margarete Cristiane de Costa Trindade Amorim², \\ João Lima Sant'Anna Neto $^{2}$ y Vincent Dubreuil ${ }^{3}$
}

\begin{abstract}
RESUMO
Este trabalho tem como objetivo analisar a estrutura térmica do clima urbano com base na interpretação do canal termal do satélite Landsat 7 e de medidas de superfície. Identificou também como se processa a produção do clima urbano, partindo de uma análise das formas de estruturação do espaço, das características do uso do solo e dos materiais construtivos na geração de ilhas de calor e suas implicaçıes no conforto ambiental de uma cidade média de clima tropical no Brasil. Para a verificação das temperaturas do ar intra-urbana realizaramse medidas em transectos móveis nos percursos norte-sul e leste-oeste. Os dados do canal termal do Landsat-7, foram convertidos para valores de temperatura de superfície. Os resultados mostraram que o padrão de urbanização e as características do uso do solo são os responsáveis pela distribuição da temperatura gerando ilhas de calor no centro da cidade e nos bairros populares densamente construídos. Nestes últimos, devido ao elevado grau de segregação social, as altas temperaturas também provocam aumento no número de casos de doenças e morbidade, principalmente do aparelho respiratório.
\end{abstract}

Palavras chave: Clima urbano, ilha de calor, canal termal, conforto térmico.

\begin{abstract}
This study aims to examine the thermal structure of the urban climate based on the interpretation of the satellite Landsat 7 (thermal channel) and measures for the area. It identifies how the production of urban climate develops based on an analysis of the structure of space forms and characteristics of land use and constructive materials in the generation of heat islands and their implications in environmental comfort in a tropical climate medium size city at Brazil. To check intra-urban air temperature, measures were carried out in mobile transects in the North-South and East-West routes. Thermal Channel data of Landsat-7, were converted to surface values. The results showed that the pattern of urbanization and characteristics of land use are responsible for the distribution of temperature generating heat islands in downtown and popular densely built neighborhoods. In those cases the highest indexes of social segregation added to higher temperature also provokes elevation in the number of illnesses and morbidity cases, mostly of respiratory diseases.
\end{abstract}

Key words: Urban climate, heat island, thermal channel, thermal comfort.

1 Artículo recibido el 18 de octubre de 2008 y aceptado el 13 de abril de 2009.

2 Departamento de Geografia, Faculdade de Ciências e Tecnologia, Universidade Estadual Paulista-
UNESP (Brasil). E-mail: mccta@fct.unesp.br; joaolima@fct.unesp.br

3 Centro de Desenvolvimento Sustentável-CDS, Universidade de Brasília (Brasil).

E-mail: vincent. dubreuil@uhb.fr 
As áreas urbanas se constituem como pólos de atração populacional. Como a segregação sócio-espacial é uma das características do modelo de desenvolvimento em geral e, do brasileiro, em particular, os bairros populares têm sido estabelecidos nas periferias urbanas, em grande parte utilizando materiais construtivos inadequados tanto do ponto de vista da qualidade de vida, quanto da eficiência térmica.

Esta hipótese direciona o trabalho cujo objetivo foi analisar a estrutura térmica do clima urbano com base na interpretação do canal térmico do satélite Landsat 7 e de medidas de superfície por meio da realização de transectos. Além disso, buscou identificar como se processa a produção do clima urbano em cidades de porte médio do oeste paulista, partindo de uma análise das formas de estruturação do espaço, das características do uso do solo e dos materiais construtivos na geração de ilhas de calor e suas implicaçıes no conforto ambiental.

A vantagem de se utilizar as imagens de satélite para este tipo de estudo decorre do fato de serem úteis para estimar a temperatura da superfície, dependendo do tipo de uso e ocupação do solo. Trata-se apenas indiretamente da temperatura do ar ligada às medidas em abrigos por meio do balanço da energia local. As imagens de satélite podem também ajudar a compreender a distribuição das fontes de calor dentro de uma área urbana que levam à formação das ilhas de calor urbanas.

Este artigo apresenta uma caracterização da área de estudo, considerando-se o processo de ocupação do oeste paulista, assim como a expansão territorial de Presidente Prudente. Na seqüência são discutidas questıes referentes aos materiais construtivos e ao conforto térmico, bem como as características do clima regional. Depois de explicitados os procedimentos utilizados na pesquisa são apresentados os resultados evidenciando-se a estrutura térmica intra-urbana tendo como referência tanto os registros de superfície como a interpretação da imagem tratada do canal termal do Landsat 7. O trabalho é finalizado com uma reflexão sobre o clima urbano e a segregação sócio-espacial.

\section{Caracterização da área de estudo}

Na passagem do século XIX para o século XX, o Brasil possuía pouco mais de 17 milhies de habitantes, em sua maior parte, vivendo numa estreita faixa costeira, apesar de seus 8,5 milhies de $\mathrm{Km}^{2}$ de extensão.

O oeste do Estado de São Paulo, neste período, ainda contava com expressiva população indígena e, a partir da década de 1910, aventureiros iniciavam a conquista do "sertão" para a incorporação de novas terras e a expansão de atividades agropecuárias.

A cidade de Presidente Prudente, principal núcleo urbano desta região que ocupa uma área aproximada de 20.000 $\mathrm{km}^{2}$, foi fundada em 1917, primeiramente dedicada às atividades pastoris e posteriormente, com a chegada da ferrovia, inicia-se a agricultura comercial (Figura $\mathrm{N}^{\circ} 1$ ).

Fatores naturais favoreceram a expansão da cultura cafeeira, que entre as décadas de 1940 a 1970 foi a responsável pelo rápido crescimento demográfico regional, bem como pela estruturação do território (Abreu, 1972).

O desmatamento acelerado das matas e florestas pelas atividades agropastoris e o assoreamento da rede hidrográfica marcaram profundamente a degradação das paisagens naturais e mudanças no ciclo hidrológico. Há indícios de que este processo de ocupação tenha provocado aumento da temperatura e concentração pluvial, modificando o regime climático.

Nas áreas urbanas, o aumento da temperatura, segundo Amorim (2000), foi ainda maior por causa da concentração de edificaçıes e da impermeabilidade do solo. Além destes fatores, há que se considerarem os materiais construtivos utilizados, 
principalmente pela população de baixa renda, que geram maior inércia térmica e desconforto humano.

\section{Povoamento e expansão territorial urbana}

O primeiro censo demográfico da região registrava em 1920, apenas 846 pessoas na área urbana de Presidente Prudente e pouco mais de 4.000 habitantes na zona rural. Com a chegada da Ferrovia (Companhia Sorocabana de Estradas de Ferro), vieram migrantes de várias regiıes do país, além de um grande contingente de italianos e japoneses que se dedicaram a agricultura cafeeira, principal produto de exportação do
Brasil até a primeira metade do século XX. A população local aumentou rapidamente até a década de 1970, diminuindo o ritmo a partir de então, devido a erradicação do café e a substituição das principais atividades agrícolas, pela criação de gado bovino. Esta mudança na estrutura agrária ocasionou o êxodo rural provocando um rápido processo de urbanização (Figura $\mathrm{N}^{\circ}$ 2).

Como a expansão territorial não foi acompanhada da respectiva estrutura de serviços e de equipamentos urbanos, uma parcela significativa da população vivia e ainda vive sob condiçıes inadequadas do ponto de vista da qualidade de vida e de indicadores de sustentabilidade.



Fonte: IBGE, 2008. 
A área urbana de Presidente Prudente apresenta grande diversidade de ocupação do solo, pois os bairros mais antigos (construídos entre as décadas de 1950 e 1970) são densamente construídos e com significativa cobertura vegetal arbórea nas ruas e fundos de quintais.

Por outro lado, as áreas residenciais que surgiram nas décadas de 1980/1990, que são a grande maioria, apresentam-se com edificaçıes esparsas, com gramado e vegetação arbórea. Neste mesmo período, para atender a demanda por habitação das classes populares, foram construídos os conjuntos habitacionais e loteamentos destinados à população de baixa renda com terrenos menores e materiais construtivos menos adequados ao clima tropical e, ao conforto térmico e ambiental (paredes finas e coberturas de fibrocimento, ou asbestos), que armazenam muito calor e produzem inércia térmica.

A expansão territorial urbana tem privilegiado o setor ocidental da cidade devido tanto às questıes políticas e econômicas como pelas características do relevo. Nesta área os divisores de água apresentam perfis convexos mais alongados, formando interflúvios mais suaves e separados entre si por vales menos estreitos, representando hoje cerca de $80 \%$ do total da malha urbana. No quadrante Leste o relevo possui declives acentuados que dificultam a expansão da malha urbana, onde habita população de baixa renda.

\section{Os materiais construtivos e o conforto térmico}

A expansão territorial urbana é caracterizada pelo aumento das áreas edificadas e pavimentadas que geram inércia térmica e a produção de calor. As ilhas de calor não causam apenas desconforto térmico em ambientes de clima tropical, mas são responsáveis também, pelo aumento da demanda por energia e por ambientes urbanos insalubres que afetam a saúde humana.

As coberturas (telhados) são as principais responsáveis pelo calor produzido tanto no interior quanto no entorno das edificaçıes. Este calor é determinado pelas variáveis de albedo (reflectância) e emissividade dos materiais. O albedo representa a porção da radiação solar incidente, que é refletida pelo material, enquanto a emissividade determina o desempenho térmico caracterizado pela temperatura superficial.

Figura $\mathrm{N}^{\circ} 2$

Crescimento populacional de Presidente Prudente (1920/2007)



Fonte de dados: IBGE, 2008. 
Assim, superfícies com elevado albedo e emissividade tendem a permanecerem mais frias quando expostas à radiação solar, pois absorvem menos radiação e emitem mais radiação térmica para o espaço, transmitindo menos calor para seu entorno. Ao contrário, quanto menor for o albedo e a emissividade maior será a absorção de calor e sua permanência no ambiente de entorno.

Diversos tipos de materiais construtivos têm sido utilizados nas edificaçıes em áreas urbanas. No oeste paulista prevalece o uso de três tipos de materiais de cobertura: as telhas cerâmicas, as de fibrocimento e as metálicas (alumínio, zinco e aço galvanizado). As coberturas cerâmicas são mais utilizadas em residências de classe média e alta, as de fibrocimento prevalecem nos bairros e conjuntos habitacionais de população de baixa renda e as metálicas nas edificaçıes comerciais e industriais.

Em função de suas propriedades físicas, os materiais de cobertura apresentam as seguintes (Quadro $N^{\circ} 1$ ) respostas térmicas (Ferreira e Prado, 2003).

\section{Características climáticas regionais}

O clima tropical continental sub-úmido do centro oeste do Brasil, caracteriza-se por duas estaçıes do ano bem definidas: um verão quente e chuvoso de outubro a março e um inverno ameno e seco de abril a setembro. Entretanto, diante da forte irregularidade climática da região, explicada por sua localização na latitude do trópico de capricórnio, área de conflito entre os sistemas tropicais e extra-tropicais, Presidente Prudente apresenta uma variabilidade sazonal acentuada (Figura $N^{\circ} 3$ ).

De modo geral, os sistemas tropicais prevalecem na região a maior parte do ano, ora com o seu ramo atlântico, mais úmido, ora com trajetórias continentais, mais quentes e secas. No período de primavera e verão, as temperaturas diárias oscilam entre os $20^{\circ} \mathrm{C}$ e $32^{\circ} \mathrm{C}$, com máximas absolutas próximas aos $40^{\circ} \mathrm{C}$. Nesta época do ano concentra-se cerca de $75 \%$ da precipitação anual de $1.300 \mathrm{~mm}$.

Quadro No 1

Temperatura superficial dos materiais (ASTM E 1980-984)

\begin{tabular}{|l|c|c|c|c|}
\hline Material & Albedo (a) & $\begin{array}{c}\text { Emissividade } \\
(\mathrm{e})\end{array}$ & $\begin{array}{c}\text { Temperatura } \\
\text { superficial } \\
\left({ }^{\circ} \mathrm{C}\right)\end{array}$ & $\begin{array}{c}\text { Diferença de } \\
\text { temperatura entre } \\
\text { o ar e o material }\end{array}$ \\
\hline Ceraimica vermelha & 0,53 & 0,9 & 36,8 & $-0,1$ \\
Ceraimica branca & 0,54 & 0,9 & 36,2 & $-0,6$ \\
Fibrocimento & 0,34 & 0,9 & 47,1 & $+10,3$ \\
Alumínio s/pintura & 0,57 & 0,05 & 69,4 & $+32,6$ \\
Alumínio cores claras & $0,40-0,47$ & 0,9 & $40,1-43,3$ & De $+3,2$ a $+6,5$ \\
Aluminio cores escuras & $0,26-0,38$ & 0,9 & $45,0-51,4$ & De $+8,1$ a $+14,5$ \\
Aço galvanizado sem pintura & 0,57 & 0,25 & 57,9 & $+21,1$ \\
\hline
\end{tabular}

Fonte: Ferreira e Padro, 2003.

4 ASTM E 1980-98: Standart Pratice for Calculating Solar Reflectance Index. 
No outono/inverno as temperaturas decrescem ligeiramente, mas permanecem elevadas, à exceção dos episódios das invasies do anticiclone polar, quando as temperaturas mínimas oscilam entre $15^{\circ} \mathrm{C}$ e $20^{\circ} \mathrm{C}$, com valores absolutos que podem chegar a $0^{\circ} \mathrm{C}$.
A temperatura média anual (1969/2007) tem oscilado, entre $21^{\circ} \mathrm{C}$ e $24^{\circ} \mathrm{C}$, de forma ascendente desde que a expansão da área urbana do município ultrapassou os limites da estação meteorológica, como demonstra a Figura $\mathrm{N}^{\circ} 4$ sobre a evolução das temperaturas no período de registro.

Figura $\mathrm{N}^{\circ} 3$

Climograma de Presidente Prudente (1969/2007)

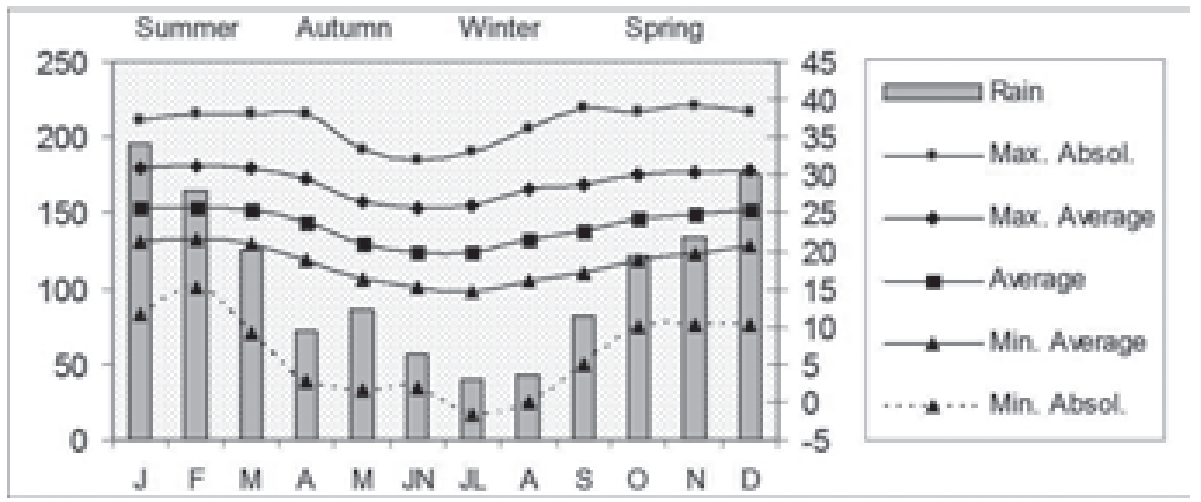

Fonte de dados: Estação Meteorológica localizada na FCT/UNESP.

Figura $\mathrm{N}^{\circ} 4$

Evolução da temperatura média anual de Presidente Prudente



Fonte de dados: Estação Meteorológica localizada na FCT/UNESP. 
Observa-se um aquecimento de $1,7^{\circ} \mathrm{C}$ em menos de 40 anos.

\section{Procedimentos metodológicos}

O referencial teórico deste trabalho baseou-se na concepção dos canais de percepção do clima urbano proposto por Monteiro (1976) e Monteiro e Mendonça (2004), enfatizando o canal termo-dinâmico como o principal responsável pelo fator de conforto térmico.
Para a verificação das temperaturas do ar intra-urbana realizaram-se medidas em transectos móveis nos percursos norte-sul (42 registros) e leste-oeste (78 registros) em cinco dias representativos do verão e outros cinco do inverno de 2002. Esse procedimento se repetiu em três dias do mês de julho de 2003, sob condiçıes atmosféricas estáveis (céu claro e baixa velocidade do vento), como mostra a Figura $N^{\circ}$ 5. Foram utilizados termômetros digitais, com os sensores presos em haste de madeira

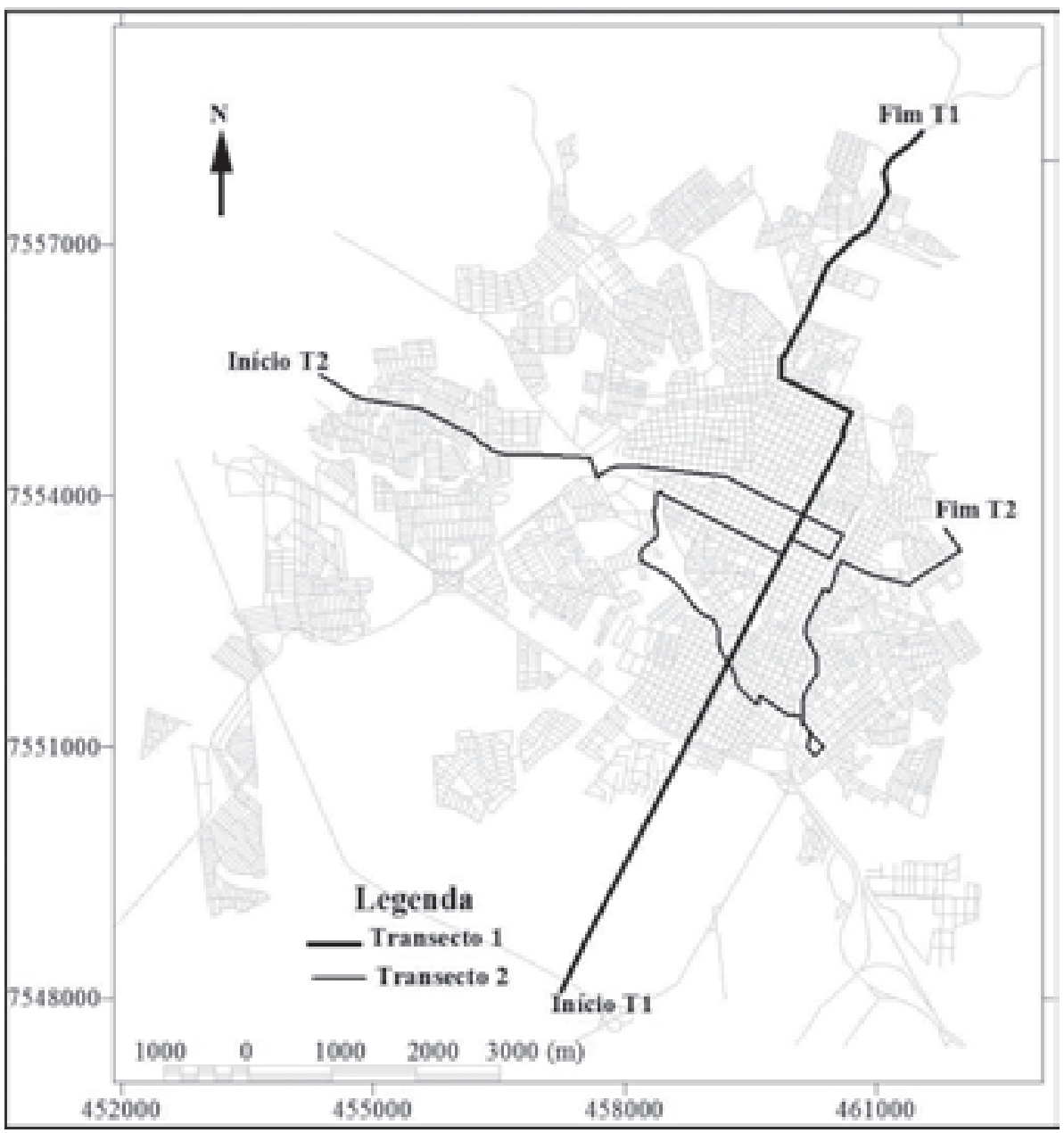

Fonte: Carta topográfica da Prefeitura Municipal de Presidente Prudente, 1995. 
com $1,5 \mathrm{~m}$ de comprimento, acoplados naô ateral de dois veículos que saíram da periferia (rural), passando pelo centro, chegando ao extremo oposto da cidade. As mediçıes foram efetuadas entre $20 \mathrm{hrs}$ e 20:45 hrs, por se tratar do horário mais adequado uma vez que as temperaturas não experimentam mudanças rápidas.

Os sistemas atmosféricos regionais que atuaram nos dias de medição de campo foram analisados por meio de cartas sinóticas de superfície disponibilizadas no site da Marinha do Brasil ${ }^{5}$ e das imagens de satélite Goes ${ }^{6}$.

A imagem de satélite utilizada foi adquirida no site Global Land Cover Facility. A única imagem disponível neste setor (WRS 222-075), próxima do período de realização do transecto móvel foi de 21 de Março de 2001. Essa imagem foi utilizada porque se considerou que não ocorreram muitas mudanças no uso e na ocupação do solo entre 2001, 2002 e 2003. Os dados do canal termal do Landsat-7, possui resolução espacial de 60 metros e as temperaturas foram convertidas para valores de superfície considerando-se valor fixo igual a 1 de emissividade.

Para a análise dos resultados das medidas coletadas no transecto foram elaboradas cartas de isotermas, através do Software Surfer for Windows, permitindo assim a identificação da variação da temperatura nos diferentes pontos da cidade.

\footnotetext{
5 Disponível em Internet: www.mar.mil.br

6 Disponível em Internet: http://satelite.cptec.inpe.br /imagens
}

\section{A estrutura térmica intra-urbana}

A resposta térmica da estrutura urbana demonstrou que a urbanização e as características do uso do solo são responsáveis pela distribuição da temperatura do ar gerando ilhas de calor nos bairros densamente construídos, ou com a concentração de materiais construtivos de grande potencial energético de emissividade e reflectância. Este padrão de distribuição, entretanto, pode se modificar em função da direção e velocidade do vento que desloca estas ilhas de calor para outras áreas da cidade. Foram observadas ilhas de calor de forte magnitude, com diferenças entre o ponto mais quente e o ponto mais frio entre $3,6^{\circ}$ $\mathrm{C}$ e $5,6^{\circ} \mathrm{C}$ em dias representativos do verão e de $4,9^{\circ} \mathrm{C}$ a $9,6^{\circ} \mathrm{C}$ no inverno. As diferenças foram menores nos dias com ventos um pouco mais fortes, $3,0 \mathrm{~m} / \mathrm{s}$ a 4,0 $\mathrm{m} / \mathrm{s}$ (Quadro No 2).

Durante a noite a cidade gera ilhas de calor com o aumento da temperatura do meio rural e bairros menos densamente construídos em direção aos bairros densamente construídos e o centro. Além da densidade de construçıes os materiais utilizados também contribuem para o armazenamento do calor.

Na maioria dos estudos de ilha de calor realizado no período noturno, o centro da ilha é bem definido e freqüentemente está localizado no centro da cidade com maior densidade de construçıes ou nos bairros industriais.

Quadro $N^{\circ} 2$

Temperaturas máximas, mínimas e diferenças térmicas entre os pontos

\begin{tabular}{|l|r|r|r|r|r|r|r|r|r|r|r|r|r|}
\hline & \multicolumn{10}{|c|}{2002} & \multicolumn{3}{|c|}{2003} \\
\hline Temp. ("C) & $15 / 1$ & $16 / 1$ & $17 / 1$ & $18 / 1$ & $23 / 1$ & $14 / 7$ & $16 / 7$ & $17 / 7$ & $23 / 7$ & $25 / 7$ & $21 / 7$ & $22 / 7$ & $23 / 7$ \\
Máxima & 27,5 & 26,2 & 26,3 & 25,9 & 27,8 & 17,9 & 22,3 & 20,1 & 22,3 & 26,7 & 26,7 & 27,3 & 26,7 \\
Mínima & 21,9 & 22,6 & 21,1 & 21,9 & 24,2 & 11,9 & 14,8 & 14,7 & 17,4 & 17,1 & 18,5 & 18,7 & 18,7 \\
Diferença & 5,6 & 3,6 & 5,2 & 4,0 & 3,6 & 6,0 & 7,5 & 5,4 & 4,9 & 9,6 & 8,2 & 8,6 & 8 \\
\hline
\end{tabular}

Fonte: Trabalho de campo-janeiro e julio de 2002 e 2003. 
Em Presidente Prudente, contudo, foi detectado pelo menos duas células separadas da ilha de calor central, que podem ser diretamente atribuídas aos materiais construtivos. Primeiramente, observou-se uma célula maior de ar mais quente localizada na zona central em direção a porção norte e sul da cidade, onde estão localizados os bairros mais antigos e densamente construídos. À medida que a densidade de construçıes diminui, verificou-se a queda na temperatura em direção ao meio rural.

A segunda célula localizou-se na porção oeste da cidade, onde se encontram dois conjuntos habitacionais densamente construídos. As temperaturas nesta célula, embora também elevadas em comparação a outros pontos da cidade, foram de $1^{\circ} \mathrm{C}$ a $2^{\circ}$ $\mathrm{C}$ mais baixas em relação ao centro. Assim, além da temperatura ser ligeiramente mais baixa do que no centro da cidade, seu tamanho foi bem menor em relação ao centro e seu entorno.

A diminuição na densidade de construção produz um efeito pronunciado no que se refere à quebra de continuidade da distribuição das temperaturas mais elevadas.

Sob condiçıes de calmaria e velocidade do vento de $0,5 \mathrm{~m} / \mathrm{s}$, entre as células da porção oeste e a da área central, mesmo estando inserido na malha urbana, foram observadas temperaturas mais baixas. (Figuras $\mathrm{N}^{\circ} 6, \mathrm{~N}^{\circ} 7$ e $\mathrm{N}^{\circ} 8$ ).

O intervalo das temperaturas mais baixas entre as duas principais células de temperaturas mais elevadas, foi quebrado no dia 17/7, devido à presença de ventos fracos de sudeste, entre $1 \mathrm{~m} / \mathrm{s}$ às $20 \mathrm{hrs} \mathrm{e} 3 \mathrm{~m} / \mathrm{s}$ às 21 hrs. O movimento do ar foi suficiente para homogeneizar as temperaturas mais



Fonte: Elaboração própria. 
Figura $\mathrm{N}^{0} 7$

Presidente Prudente: temperatura do ar, 21/07/2003, 20 hrs



Fonte: Elaboração própria.

Figura $\mathrm{N}^{\circ} 8$

Presidente Prudente: temperatura do ar, 22/07/2003, 20 hrs



Fonte: Elaboração própria. 
Figura $\mathrm{N}^{\circ} 9$

Presidente Prudente: temperatura do ar, 17/07/2002, 20 hrs



Fonte: Elaboração própria.

elevadas por toda a porção oeste da cidade, independentemente da densidade de construçıes. O calor produzido na área mais densamente construída foi distribuído pelo vento predominante de sudeste e apenas o meio rural e os bairros localizados ao leste do centro da cidade tiveram temperaturas mais baixas neste dia (Figura $N^{\circ}$ 9).

Os limites das áreas construídas em direção à zona rural definiram claramente o limite da ilha de calor. Porém, as áreas intra-urbanas com menor densidade de construçıs, estiveram sujeitas as temperaturas mais elevadas, por ocasião de brisas provenientes do quadrante leste, onde se localizaram, habitualmente, no período noturno, as temperaturas mais elevadas.

Em noites sem nebulosidade, como as observadas neste estudo, no ambiente rural os fundos de vales foram favoráveis às temperaturas mais baixas, como se observou nas porçıes sul, oeste e leste da mancha urbana.
Os córregos localizados no ambiente urbano, em sua maioria, foram canalizados. No período noturno, os pontos com altitudes mais baixas, não provocaram a "quebra" da ilha de calor principal encontrada na cidade. Até mesmo o Parque do Povo, onde o Córrego do Veado foi canalizado e a área foi coberta por vegetação rasteira e arbórea, o intenso fluxo de veículos e o uso do solo nas avenidas que margeiam o fundo de vale (comercial e residencial), fizeram com que as temperaturas permanecessem elevadas.

Em pesquisa realizada anteriormente, Amorim (2000), mostrou que no verão as magnitudes mais fortes das ilhas de calor (entre $4^{\circ} \mathrm{C}$ e $6^{\circ} \mathrm{C}$ ) durante o dia foram observadas principalmente entre $10 \mathrm{hrs}$ e 16 hrs, coincidindo com os horários de maior insolação e maior aquecimento diurno e intensificando assim o desconforto térmico presente no verão das cidades tropicais. Nos outros horários (7 hrs, 8 hrs, 9 hrs, 17 hrs e $18 \mathrm{hrs}$ ), foram freqüentes ilhas de calor de 
média magnitude (entre $2^{\circ} \mathrm{C}$ e $4^{\circ} \mathrm{C}$ ), mas, também foram registradas, em alguns dias, ilhas de calor de forte magnitude, embora com menor freqüência.

Naquela pesquisa, no verão os principais responsáveis pelas maiores diferenças entre os pontos mais quentes foram às áreas densamente construídas e com pequena quantidade de vegetação. A presença da arborização nas ruas e fundos de quintais, os materiais construtivos mais adequados (telhas cerâmicas) e os terrenos maiores, a exemplo das Figuras $N^{0} 10$ e $N^{0} 11$, exerceram papel fundamental nesta estação, pois as áreas densamente arborizadas e, em alguns casos, com alta densidade de construçıes tiveram as temperaturas mais baixas, mas as áreas densamente construídas e com pouca vegetação ou com poucas construçıes, e também sem vegetação, tiveram as temperaturas mais altas, como se observa, na Figura $N^{\circ} 12$, representativa do verão, no período de maior aquecimento diurno.

A localização das temperaturas mais elevadas relaciona-se diretamente à densidade de construçıes e o calor noturno é atribuído à liberação do calor estocado durante o dia pelas edificaçıes, conforme se observa na imagem tratada do canal termal do Landsat 7 (Figura № 13).

Figura $\mathrm{N}^{\circ} 10$

Bairro de classe média



Fonte: Imagem do Google Earth, 2007.
As temperaturas intra-urbanas medidas através dos transectos móveis, mensuram as condiçıes gerais do ambiente de entorno, e revelam-se importantes como indicadores do aquecimento local. Entretanto, não são capazes de revelar as temperaturas específicas dos alvos da superfície urbana. O uso da carta termal do Landsat, mostrouse particularmente interessante, pois ao contrário das mensuraçıes anteriores, estes revelam a temperatura efetiva dos alvos terrestres, em escala areolar. Assim, pode-se observar que as áreas da cidade em que os materiais construtivos utilizados são menos eficientes do ponto de vista da emissividade e que armazenam maior quantidade de calor, apresentam temperaturas significativamente maiores.

Portanto, a análise da carta termal demonstra que as temperaturas mais elevadas encontram-se nos conjuntos habitacionais e bairros residenciais onde predominam coberturas de fibrocimento (asbestos), além da maior densidade de construção, fatos este que não foram identificados a partir das mediçıes dos transectos móveis. Como resultado desta análise comparativa, observa-se que numa perspectiva de ambiente de entorno, as áreas centrais, no geral, são mais quentes, mas, quando medem-se os alvos específicos, reveladores da estrutura

Figura $\mathrm{N}^{\circ} 11$

Casa de classe média com telha cerâmica, grades vazadas e janelas amplas

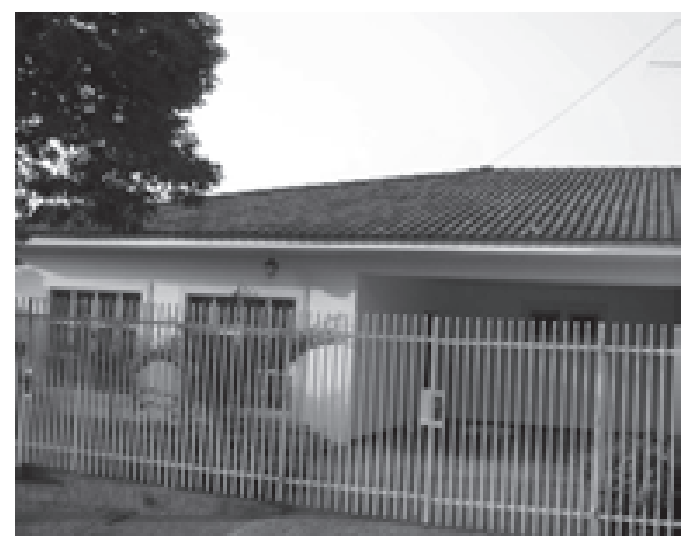

Fonte: Coleção pessoal dos autores. 
Figura $N^{\circ} 12$

Presidente Prudente: temperatura do Ar, 17/01/1999, 15 hrs

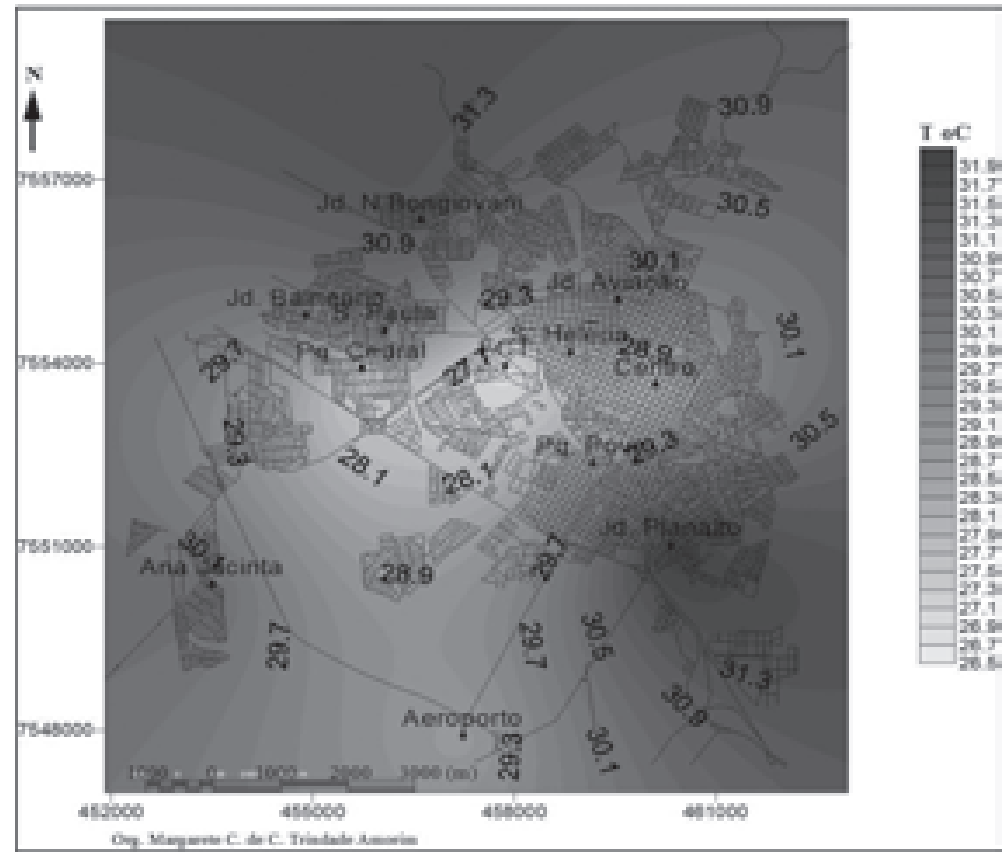

Fonte: Adaptado de Amorim, 2000.

Figura $\mathrm{N}^{\circ} 13$

Presidente Prudente: temperatura da superfície: imagem do Landsat 7, canal termal



Fonte: Elaboração própria. 
construtiva da cidade, as áreas mais quentes, não são as centrais, mas, sim, aquelas em que os padries construtivos individuais apresentam menor albedo e menor emissividade.

\section{Clima urbano e segregação socioespacial}

A estrutura térmica da área urbana interpretada na imagem tratada do Landsat 7, traduz a ocupação atual, a densidade de construçıes e a arborização. Nos bairros densamente construídos, principalmente nos conjuntos habitacionais com coberturas de fibrocimento e com pequena quantidade de vegetação arbórea nas ruas e fundos de quintais, as temperaturas detectadas na superfície foram as mais elevadas, atingindo $25^{\circ}$ C. Nos bairros com terrenos maiores, em que as edificaçıes não ocupam toda a área e, com a presença de vegetação arbórea esparsa, as temperaturas foram menores $\left(21^{\circ} \mathrm{C}\right)$. Nos parques e demais áreas verdes urbanas, as temperaturas variam entre $19^{\circ} \mathrm{C}$ e $21^{\circ} \mathrm{C}$, em função do tipo de vegetação mais rasteira ou arbórea (Figura № 13).

Assim, pode-se afirmar que a presença da vegetação tem papel fundamental para amenizar as altas temperaturas durante o dia, fato também observado tanto na imagem tratada do Satélite Landsat 7, como

Figura $\mathrm{N}^{\circ} 14$

Bairro popular com cobertura de fibrocimento

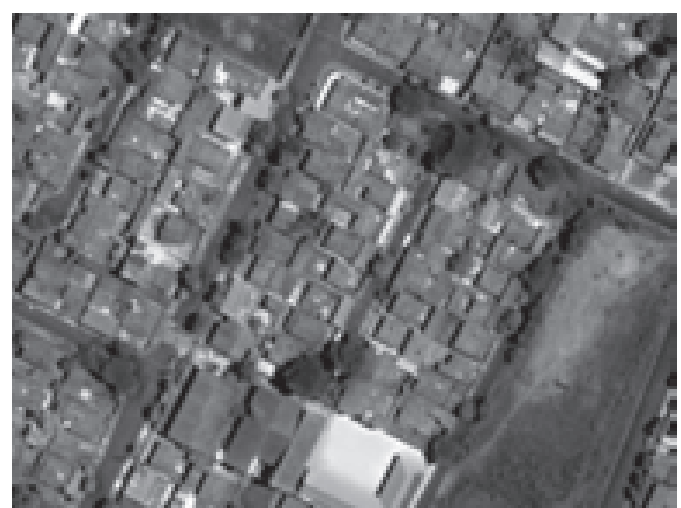

Fonte: Imagem do Google Earth, 2007. nos registros diurnos realizados por Amorim (2000). Entretanto, no período noturno, conforme se verificou nos resultados dos transectos, a presença da vegetação nas ruas e fundos de quintal não contribui para amenizar as altas temperaturas em áreas densamente construídas. As temperaturas mais baixas foram observadas nos bairros periféricos pouco construídos, nas áreas rurais e fundamentalmente nos fundos de vale do meio rural próximo à cidade. Os dois transectos se iniciavam e terminavam no ambiente rural onde se configuraram nitidamente as mais baixas temperaturas nesses pontos, nos fundos de vale pouco edificados e nos bairros próximos ao rural, que tem as altas temperaturas amenizadas pelas brisas que se formam devido ao aquecimento.

Em cidade de médio porte de clima tropical continental a produção do clima urbano é resultado da interação entre a radiação recebida e a refletida basicamente pelos tipos de materiais construtivos de edificaçıes de uso residencial que armazenam o calor durante o dia e são liberados nas primeiras horas após o por do sol. Como as cidades tropicais são naturalmente quentes, as ilhas de calor são responsáveis pela intensificação do desconforto térmico e, portanto, considerase como um indicador de qualidade ambiental urbana.

\section{Figura $N^{\circ} 15$}

Casa popular com cobertura de fibrocimento, janelas pequenas e muros altos

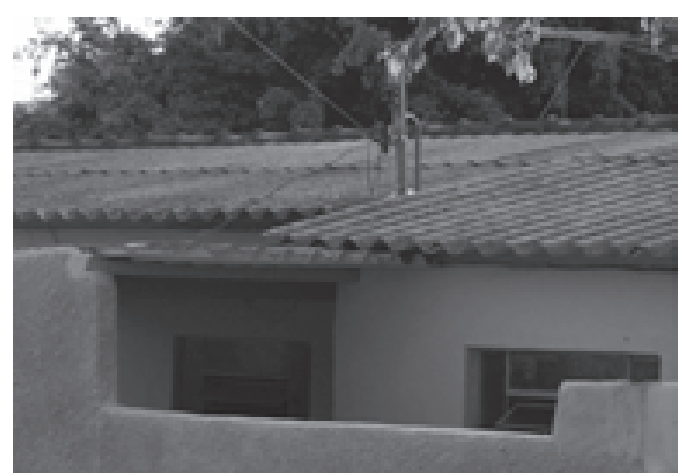

Fonte: Coleção pessoal dos autores. 


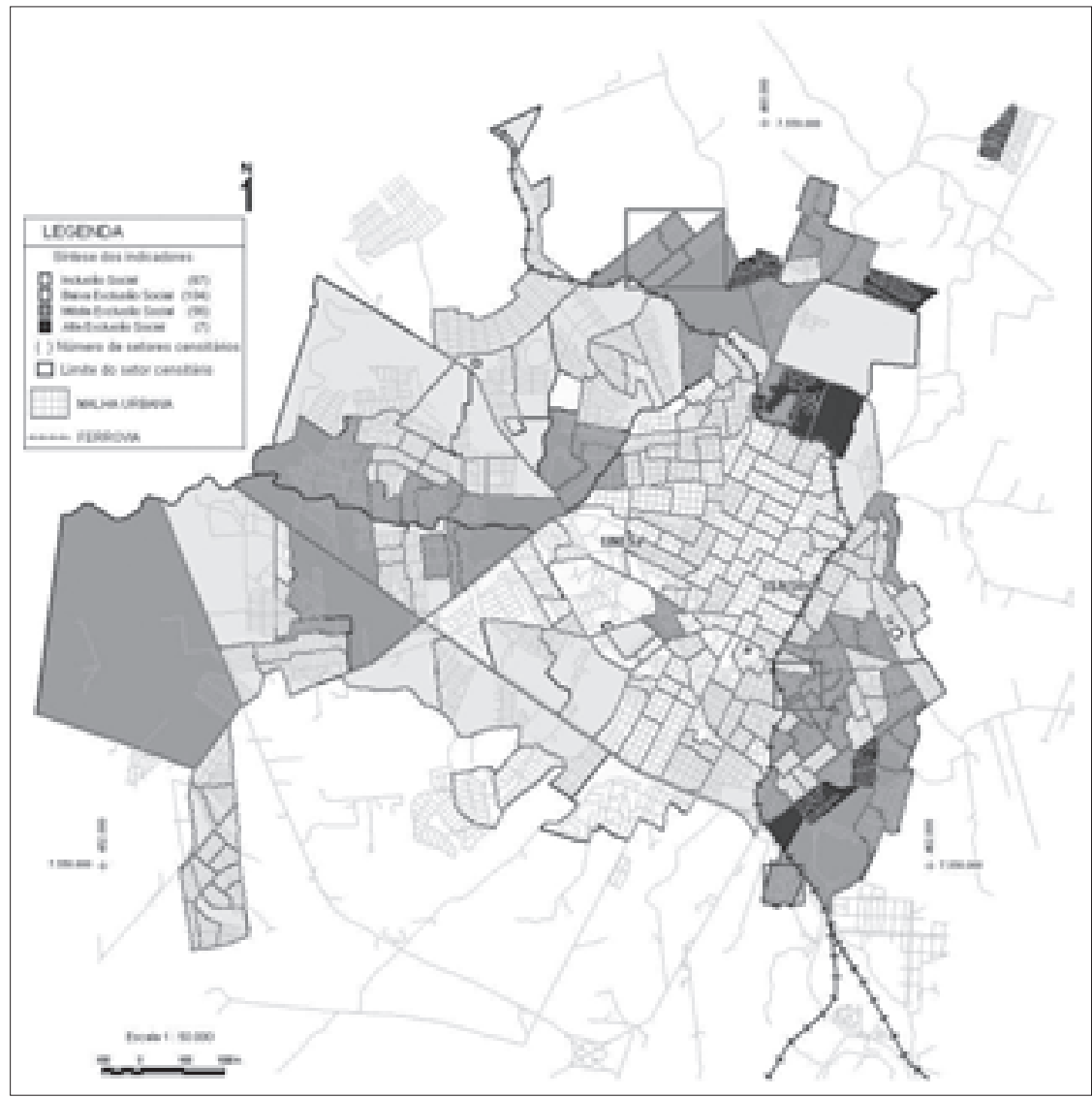

Fonte de Dados: CEMESPP (FCT/UNESP)/IBGE, 2000.

A população de baixa renda, impossibilitada de adquirir materiais construtivos mais adequados e lotes urbanos de maior tamanho, é a mais prejudicada pelos efeitos adversos do calor armazenado nas edificaçıes. Na maior parte dos dias de primavera e verão, as temperaturas diurnas do ar oscilam entre $30^{\circ} \mathrm{C}$ e $35^{\circ} \mathrm{C}$ que somadas ao calor produzido e armazenado pelas coberturas de fibrocimento, como, por exemplo, as observadas nas Figuras $\mathrm{N}^{\circ} 14 \mathrm{e}$ $N^{\circ} 15$, podem superar os $45^{\circ} \mathrm{C}$, expondo a população, notadamente os idosos e crianças (que permanecem mais tempo dentro das residências), a situaçıes de insalubridade, que se manifestam na forma de enfermidades como doenças respiratórias e do aparelho circulatório.
Desta forma, as áreas urbanas de maior segregação socioespacial, são as mesmas em que é maior a morbidade por doenças respiratórias, que são muito dependentes das influências climáticas (Figura $N^{\circ} 16$ ). São, também, as áreas em que se produz a maior intensidade das ilhas de calor, ao contrário das áreas metropolitanas, em que o dinamismo da circulação viária e as fontes de emissão de partículas acabam sendo majoritários.

O uso da imagem de satélite foi decisivo para evidenciar as fontes de calor (confirmadas com os transectos térmicos) dentro da cidade na origem da formação das ilhas de calor urbanas. 
As temperaturas extremas localizam-se, na maioria dos locais, nas áreas em que se encontram os bolsies de pobreza, especialmente nas áreas de média e alta exclusão social, como se pode verificar na comparação das Figuras $N^{\circ} 13$ e $N^{\circ} 16$. Caracterizadas por habitaçıes precárias de população de baixa renda, a maior parte das unidades habitacionais com temperaturas elevadas é formada por residências com telhado de fibras de concreto e por meias paredes de blocos cerâmicos. Ambos os materiais não são isolantes térmicos, o que propicia o intenso ingresso de ar quente para o interior da moradia.

Num episódio de onda de calor, uma família de baixa renda, sem o vestuário adequado e subalimentada, torna-se potencialmente vulnerável, por exemplo, aos casos de doenças respiratórias. Menos provida de defesas aos agentes causadores das enfermidades, esta população está mais suscetível a contrair doenças e menos apta a sair mais rapidamente deste quadro de agravo.

Assim, o clima também se constitui em importante fator de qualidade de vida e indicador de justiça social.

\section{Referências bibliográficas}

ABREU, D. Formação histórica de uma cidade pioneira paulista: Presidente Prudente. Presidente Prudente: Faculdade de Filosofia Ciências e Letras, 1972.
AMORIM, M. O clima urbano de Presidente Prudente / SP. Tese doutorado em Geografia. São Paulo: Faculdade de Filosofia, Letras e Ciências Humanas, Universidade de São Paulo, Brasil, 2000.

CENTRO DE ESTUDOS E DE MAPEAMENTO DA EXCLUSÃO SOCIAL PARA POLÍTICAS PÚBLICAS (CEMESPP). Dados censo demográfico. Río de Janeiro: CEMESPP, 2000. Disponível em Internet: http://www4.fct.unesp.br/grupos/cemespp/ mapas.php

FERREIRA, F. \& PRADO, R. Medição do albedo e análise de sua influência na temperatura superficial dos materiais utilizados em coberturas de edifícios no Brasil. São Paulo: Boletim Técnico da Escola Politécnica da USP, 2003.

INSTITUTO BRASILEIRO DE GEOGRAFIA E ESTATÍSTICA. Mapas IBGE. Atlas escolares. Río de Janeiro: IBGE, 2008. Disponível em Internet: http://www.ibge. gov.br/mapas_ibge/atlas.php

INSTITUTO BRASILEIRO DE GEOGRAFIA E ESTATÍSTICA. Censos demográficos e populacionais. Río de Janeiro: IBGE, 2008. Disponível em Internet: http://www.ibge. gov.br/

MONTEIRO, C. Teoria e clima urbano. São Paulo: IGEOG/USP, Série Teses e Monografias 25, 1976.

MONTEIRO, C. \& MENDONÇA, F. Clima urbano. São Paulo: Contexto, 2004. 